\title{
Letter from the President of the EANS
}

\author{
Jesus Lafuente ${ }^{1}$ (I)
}

Received: 16 October 2017 / Accepted: 25 October 2017 / Published online: 17 November 2017

(C) Springer-Verlag GmbH Austria 2017

Dear neurosurgical colleagues and friends,

As you know, recently, and during the latest EANS congress held in Venetia, I took the position as president of the European Association of Neurological Societies (EANS). I take this position with great honour and responsibility, knowing that I and the recently nominated board will meet great challenges.

I would like to take this opportunity, to thank, the SENEC (Spanish Society of Neurosurgeons) for giving me the support for the presidency, the SBNS (Society of British Neurological Surgeons) for training me as a neurosurgeon and to the members of the EANS board that convinced me to take on the presidency of such a prestigious society.

The EANS training courses, which have been running for almost 50 years, since 1971, are courses in permanent change due to constant evolution in technology, resources and surgical technique and approaches. These training courses, which happen to be the soul of the EANS, are training at present more than 600 European residents, with the intention of one great goal: the standardisation of neurosurgical training throughout all the member countries. Furthermore, the EANS board is working to make these courses also a true model to be applied in our sister continental societies such as AASNS (Asia Australasian Neurosurgical Society) and FLANC (Latin American Neurosurgical Society). The first FLANC/EANS training course, based on the current EANS training model course, will be held in the next FLANC biannual congress in Santa Cruz, Bolivia in 2018. This first course

Jesus Lafuente

jlbspine@gmail.com

1 Parc de Salut Mar, Neurosurgery, Paseo Maritimo, 08003 Barcelona, Spain will be on the spine and it will involve ten faculty members from the EANS Spine section, as well as a member of the executive office to help with the organisation.

Another great challenge for this term consists of trying to standardise neurosurgical care in all member countries; a complicated challenge, due to different factors, including cultural differences, different health systems, different ways of doing things. Our initial goal will consist of approaching the different models across Europe.

In order to standardise or approach models in Europe, EANS has tools such as JRAAC (Joint Residency Advisory and Accreditation Committee), which is formed by a group of neurosurgeons that evaluates different aspects of a neurosurgical unit, both for training and for neurosurgical care, following some minimum standards which can be consulted in the EANS/JRAAC web page. Similarly, we would like to get curriculum validation along the country members for our board exam.

Increasing our training courses to a third cycle, implicates an increase in faculty, which will have to be recruited from all country members. It is a great honour to be part of the EANS faculty, and I would like to take this opportunity to encourage different neurosurgeons of different subspecialisms to join in and be part of this outstanding EANS faculty group. Similarly, I would like to encourage all neurosurgical residents to fill in the request forms to come and join these outstanding training courses, which I believe are a unique opportunity to learn, as well as to socialise with European colleagues.

The board that I will be leading for the next 2 years is a team with wide European representation, all of whom have had a unequivocal commitment to the EANS for many years. It is a great honour for me to lead this magnificent group of neurosurgeons, with whom I share the same vision and objectives for the development of the future of this Society. 